\title{
O rádio na escola e as redes sociais
}

\author{
Jesualdo Freitas de Freitas*
}

Resumo: O texto narra a experiência em curso na Rede Municipal de Educação da SMED/POA no campo das redes sociais na educação básica. Apresenta produções dos alunos em áudio, vídeo e texto e postagem em blog. Também apresenta como possibilidade de execução de rádio poste a veiculação de produção elaborada pelos alunos, dirigidas a seus pares. Tais açóes incentivam muito aos alunos que descobrem outras possibilidades de valorizar a escola como importância em sua forma e expressão. Apresenta elementos que os jovens muito valorizam em sua faixa etária e que são recursos da Internet alcançáveis em equipamentos hoje presentes nas escolas. Também aborda sobre a expectativa de professores, um tanto atônitos, frente às diversidade de possibilidades da comunicação na atualidade, que nos faz construir enormes expectativas e muitas vezes não percebemos o quanto pode ser realizado e a grande importância de a educação básica incluir esses recursos midiáticos em seu campo. Sugerimos a Educomunicação como pertinente teoria para a realização de tais propósitos e a obtenção de suas expectativas.

Palavras-chave: Educomunicação; Expectativa; Protagonismo juvenil; Atualização escolar; produção de alunos.

Abstract: The text narrates the current experience on Social Networks in Basic Education, provided by SMED/POA to the Municipal Education System of Porto Alegre. It presents students' productions in various medias (audio, video, texts and posts in blogs). It also presents the possibility of the productions broad-

* Professor de História da Rede Pública Municipal de Porto Alegre, radialista e assessor referência do Projeto Alunos em Rede. Tem experiência no ensino Fundamental e Médio, nos últimos 10 anos atuando em Educomunicação. E-mail: alemrede2@ gmail.com 
cast in 'radio-pole' to other students. Such activities encourage the students to see school as something to be considered worth of praise for its form and expression, also using Internet resources available at schools and praised by the age group of the students involved in the project. It also deals with the astonishment of the teachers and their expectations before the new communication possibilities; these expectations can make difficult for them to realize how much can be done and the great importance of the medias' use in Basic Education. We suggest Educommunication as a relevant theory for the accomplishment of such objectives and the achievement of their expectations.

Keywords: Educommunication; Expectation; Youth leadership; Educational update; Students' productions.

\section{Apresentação}

O Projeto Alunos em Rede - Mídias Escolares, também conhecido como AlemRede, da Inclusão Digital da Secretaria de Educação da Prefeitura Municipal de Porto Alegre, aplica estratégias para a implantação da Teoria da Educomunicação na Rede Municipal. Consta de assessoria, alimentação de um blog e formação a professores e alunos do Ensino Fundamental. Como estímulo promove cobertura de eventos por parte dos alunos, bem como visitas a universidades e estúdios de rádio. Indica postagens que confirmam as ações narradas. Também com o objetivo de construir Ecossistemas Comunicativos Abertos, criativos e democráticos. Apoia-se em linguagens de mídias partindo do rádio e se estendendo a fotografia, vídeo e escrita postados em blogs. O conteúdo parte de produção em sala de aula ou da oficina pedagógica de rádio, para rodar em rádio poste na escola.

No momento algumas escolas constituíram o veículo rádio e outras estão partindo da produção de sala de aula. Pretende oportunizar aos alunos um contato em rede com seus colegas de outras escolas em encontros presenciais e virtuais possibilitando aportes de conhecimentos para que utilizem ferramentas digitais 
de comunicação na escola e além dela. No blog www.alemrede. blogspot.com há mais de 500 peças e, ainda, os blogs de várias escolas com suas produções a somar esse número. O blog tem caráter de divulgação, rede para interação de alunos e subsídios teóricos e de linguagem. Mais informações sobre o projeto você encontra no próprio blog e num texto que descreve de forma mais completa em http://websmed.portoalegre.rs.gov.br/escolas/ revistavirtualagora/educomunicacao.pdf.

No projeto, a cidadania é exercício e é também ato pedagógico real. Trabalha-se junto na construção da peça comunicativa. Nesse ato a horizontalidade na produção procede sem afetar o conhecimento e a formação do professor, ao contrário, potencializa.

\section{O Blog alemrede.blogspot.com}

É uma ferramenta de estímulo à interação, suporte em âmbito teórico, metodológico e de software, publicação veiculando a produção dos alunos, a produção de jornalistas em graduação e mestrandos com trabalhos de dissertação sobre nosso projeto.

Um pouco do projeto pode ser visto navegando no blog, sorvendo a produção dos alunos e compartilhando comentários, sendo o veículo das rádios (http://alemrede.blogspot.com/). 
Figura 1: Alunas da Escola Chico Mendes entrevistando acadêmica de jornalismo.

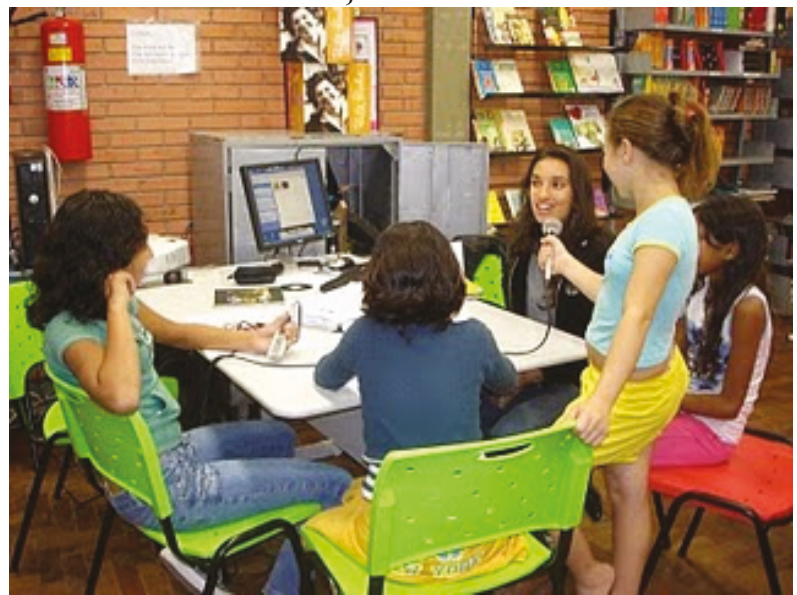

Disponível em: <http://djtaldemaiscm.blogspot.com.br/2010/07/entrevistacom-estudante-de-jornalismo.html $>$.

\section{As redes sociais e a escola}

Buscando relatar a nossa experiência de redes sociais na educação básica, percebemos que já conseguimos ter a educação básica nas redes sociais. Lançamos uma proposta de rede de alunos de escolas municipais, através da ideia de produção em mídias, partindo do rádio. Mesmo sabendo de inúmeros desafios por vir, articulamos várias ações para a construção de uma rede virtual.

Após alguns anos percebemos não atingir alguns objetivos, talvez seja melhor dizer não atingimos todas as nossas expectativas. Sempre importante, a expectativa é construtora. Percebemos com o tempo que a aparente distância entre as expectativas e a realidade revelou a realização de rede em outros formatos, valiosos, embora não tenhamos contemplado toda a expectativa inicial.

Pretendíamos que alunos interagissem com colegas de outras escolas via web, porém impedimentos de ordens diversas 
como intensas demandas de atividades dentro do cronograma cultural da escola e o fato de os alunos não portarem computadores em suas residências restringiram o diálogo on-line. Porém permanece a realização de postagens de sua produção como exemplos a seguir.

Minhas impressões sobre o FLL BRASILEIRO 2010

Bruna da Rocha, 14 anos, pela Rádio DJTALD+, aluna da Escola Victor Issler, atuou no evento como locutora-entrevistadora, fotógrafa e redatora.

Eu acho que me sai super bem aqui no evento SMART MOVE 2010 porque fiz muitas entrevistas e depoimentos que irão para nosso blog onde ficará marcado na memória, no computador para todo o mundo, já que divulgamos nosso trabalho para todos.

Achei bacana entrevistar o pessoal do RIO GRANDE DO NORTE achei legal porque eles são totalmente diferentes das pessoas que já conheci: modo de falar, de rir, de brincar e de ser e isso me chamou muito a atenção e gostei. Foi uma experiência legal.

$\mathrm{Na}$ viagem pude conhecer outras pessoas bacanas que gostavam das mesmas coisas que eu gosto. A paisagem que vi no caminho para São Paulo eu nunca tinha visto antes. Eram morros, árvores lindas, os rios e uma parte de rochas dentro dos rios mesmo. Também fizemos algumas paradas para ir ao banheiro, lanchar e até mesmo tirar fotos do lugar. No hotel em que ficamos tem uma área de lazer impressionante com piscina, mesas de jogos e uma pequena área verde onde tem um lindo pavão meio que azulado, nós do hotel em geral já tínhamos tirado muitas fotos do pavão e sua pequena família que estavam perto da área de lazer. Eu gostei muito de ter ido até SÃO PAULO, eu nunca tinha ido tão longe de casa mas dessa vez foi longe e gostei à beça do lugar fiz muitas coisas caminhei pela cidade com o sor e o Diego vi muitas praças tão lindas quanto as de Porto Alegre.........Esse passeio a São Paulo vai abrir muitas portas na minha vida de trabalho por que muitas pessoas das comunidades que compõem as escolas do município de Porto Alegre não conseguem o que eu Bruna conquistei.

GOSTARIA DE AGRADECER A SMED POR TER OPORTUNIZADO ESSA VIAGEM A SÃO PAULO,AO JESUALDO POR TUDO QUE ELE TEM NOS ENSINADO ATÉ AQUI E AO PESSOAL DO HOTEL PASSALEDO QUE NOS RECEBEU MUITO BEM NA NOSSA CHEGADA..OBRIGADA BRASIL .( http:// roboviagem2010.blogspot.com.br/2010/12/minhas-impressoes-sobreo-fll.html). 
Minha percepção do evento FLL NACIONAL 2010

Diego Pereira, 14 anos, da Rádio DJTALD+, aluno da Escola Victor Issler (atuou como locutor, fotógrafo e redator)

"O meu olhar sobre o evento FLL BRASILEIRO 2010 foi bem mais perspicaz, ao qual mesmo sem observar atento o campeonato, mas sim o que acontecia ao derredor, avaliei bem a organização, torcidas de equipe e claro, a minha equipe, rádio DJTALD + Victor Issler.

Acompanhando o evento desde Novo Hamburgo na Universidade FEEVALE, me diverti e desenvolvi pontos essenciais para qualquer entrevista, foto, vídeo e áudio. Em todos os pontos além de ter que administrar a ansiedade, o nervosismo me senti à vontade para conseguir elaborar perguntas e me aproximar mais do entrevistado. Isso tudo foi de inteira importância no evento FLL Novo Hamburgo, quanto recentemente em Indaiatuba São Paulo. Creio que estes eventos ajudarão e melhorarão a minha vida, e de outros muitos adolescentes que se interessam por educação e comunicação. Espero levar essas experiências para a vida toda e no decorrer do caminho arrecadar muitas outras. Desde então agradeço a toda a equipe do Alunos em Rede e por fim a SMED de Porto Alegre por essas imensas oportunidades. Que o espírito amigável e de união seja sempre cultivado na FLL e nos eventos por onde a Rádio passar. Muito Obrigado.”

Vacinação da Tríplice Viral no Marcírio, texto, áudio e vídeo. Disponível em: (http://radioamigosdosom.blogspot.com.br/search?updated$\max =2011-08-20 \mathrm{~T} 12: 20: 00-03: 00 \& \max -$ results $=10 \&$ start $=10 \&$ by date $=$ false $)$ 
A professora Paula Medeiros conversou com a gente sobre a vacinação da Tríplice Viral, que ocorrerá em nossa escola no dia 20 de julho (quartafeira). Ela nos contou que o objetivo desta vacina é combater o sarampo, a caxumba e a rubéola. Também comentou que esta vacinação ocorre a cada 4 anos, mas como ocor-

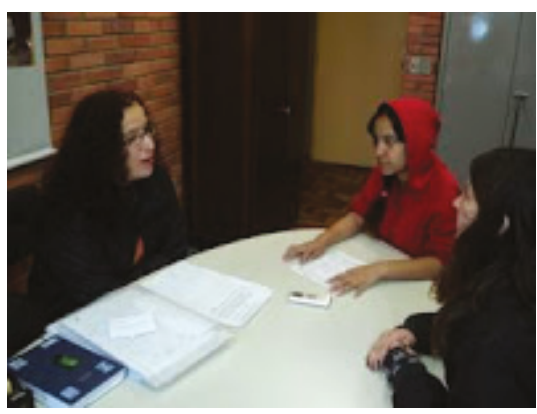

Foto: acervo Rádio Amigos do Som rerram casos de sarampo na Europa, o governo brasileiro decidiu adiantá-la.

Figura 2: Aluna Edinara entrevistando a Professora Paula Medeiros

Saiba mais ouvindo a nossa entrevista. Entrevista: Edinara Santos. Edição do áudio: Tatiana Nunes

A seguir outra matéria de 30.08.201.

Pré-conferência dos Direitos da Criança e do Adolescente da Região Partenon. Disponível em: (http://radioamigosdosom. blogspot.com.br/201 1/08/pre-conferencia-dos-direitos-dacrianca.html)

No dia 16 de agosto, a nossa Escola participou da Pré-conferência dos Direitos da Criança e do Adolescente da Região Partenon, onde compareceram 281 pessoas: 121 adultos e 160 crianças e adolescentes no Centro de Formação Profissional Murialdo.

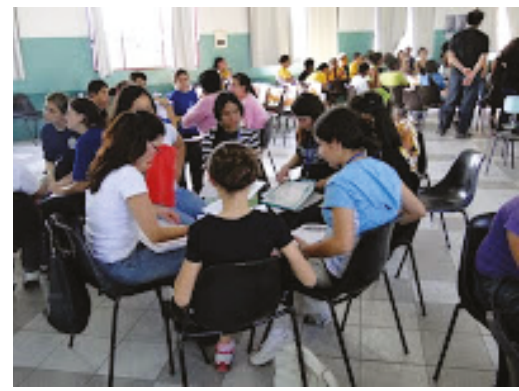

Foto: acervo Rádio Amigos do Som.

Figura 3: Panorâmica da Pré-conferência dos Direitos da Criança e do Adolescente da Região Partenon 
No início do evento aconteceu a apresentação da Banda Evolução, aqui da nossa escola e da Banda Aghata. Pouco depois formou-se a mesa de abertura, cujos participantes foram: Anelise, coordenadora da mesa; Nelcinda, presidente do CMDCA; Lisandra, assistente representante da Rede Partenon; Joel representante do Fórum de Entidades e Éverton Silveira, como palestrante que nos concedeu uma entrevista (vídeos abaixo). No evento ele falou sobre a importância do Estatuto da Criança e do Adolescente que está comemorando 21 anos de existência. Em seguida os participantes foram separados em grupos de trabalho de adultos e de adolescentes, onde houve a participação de alunos da Escola Marcírio. Os temas discutidos foram: Promoção dos direitos da criança e do adolescente; Proteção e defesa dos direitos; Protagonismo e participação de crianças e adolescentes; Controle social da efetivação dos direitos; Gestão da política nacional dos direitos humanos de crianças e adolescentes.

Houve a apresentação de um grupo de dança da Mostra Cultural do Sase Murialdo e o desfile da AMUE - Associação das Mulheres Unidas pela Esperança. Por último ocorreu a plenária, onde foram relatados os encaminhamentos dos grupos. Este evento antecede a $9^{\mathrm{a}}$ Conferência Municipal a ser realizada em outubro.

Texto e entrevista: Ingrid Velasque, 15 anos. Video: André Moraes

Essas postagens recebem comentários, em freqüência indefinida. Indicamos abaixo alguns comentários de estudantes de jornalismo referentes a uma ação do projeto visitando o Estúdio de Jornalismo do IPA, que resultou uma concentração de comentários em http://alemrede.blogspot.com.br/2010/06/ escolas-municipais-nos-estudios-de.html.

comentários:

LETÍCIA R disse...

Muito legal a troca, acredito que todos aprenderam muito. O que vcs apresentaram é uma lição de vida. Espero que surjam novos comunicadores deste projeto. Parabéns mesmo

03/07/2010 04:01:00

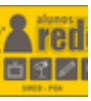

Valeu seu comentário! Você é estudante de jornalismo ou de pedagogia? 04/07/2010 18:58:00 
Anônimo disse...

Olá, sou Andressa estudante de jornalismo do Ipa, achei super interessante esta iniciativa dos alunos em criar um blog, e nele produzir entrevistas e matérias feitas pelos próprios estudantes. É um desempenho sensacional com qualidade no desenvolvimento das matérias e aprofundamento na apuração dos fatos. Gostaria de parabenizá-los pela capacidade de todos os participantes de desempenhar este belíssímo trabalho

\section{8/07/2010 22:54:00}

Klaus Fiedler disse...

Sou estudante de Jornalismo do IPA e gostaria de parabenizar a todos os responsáveis por esta ação. Particularmente, eu utilizo estes programas de edição de áudio no meu programa de rádio. Assim sendo, sei da grande importância que é aprender a utilizar estas ferramentas, além do mais instiga aos estudantes a aprenderem a trabalhar em equipe e, quem sabe eles gostem de trabalhar com esta área e futuramente sigam o rumo do jornalismo. Novamente, parabéns a todos por esta iniciativa. 09/07/2010 17:11:00

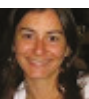

Elisângela Ribas disse...

Olá Jesualdo, estou aqui dando uma olhada na página e vendo os comentários dos meus alunos, que ótimo!

A Letícia é do Jornalismo.

Nos falamos. Um abraço

09/07/2010 21:23:00

Michelle Rossatto Neckel disse...

Oi, também sou estudante de jornalismo do IPA e parabenizo a iniciativa da Smed ao criar o Projeto Além Rede, com um blog para a publicação de material produzido por estudantes. As fotos e entrevistas são muito boas. São importantes iniciativas que dão a oportunidade aos alunos de conhecerem o meio da comunicação. E ainda podendo executar um trabalho de comunicador!!! É um grande aprendizado!

19/10/2010 20:21:00 


\section{$\lim x$ \\ - Taniel Chaves disse...}

Esse tipo de envolvimento com equipamentos de comunicação desde o ensino fundamental, ajuda as pessoas não só pelo lado profissional, como também pelo lado pessoal. A preparação deve começar assim, desde cedo, para que o aluno chegue a faculdade muito mais integrado com os assuntos propostos.

Daniel Chaves - Estudante de jornalismo.

25/10/2010 14:13:00

Anônimo disse...

O projeto Além Rede é muito interessante, pois, além de promover a interação entre os alunos, incentiva a produção de tarefas fora da sala de aula. As atividades também ajudam na escolha profissional destes jovens. Por exemplo, neste post que conta sobre a visita dos alunos do projeto Além Rede ao laboratório de rádio do IPA. Eles trocaram experiência com os acadêmicos do curso de Jornalismo e Pedagogia e essa ação demonstra que os estudantes têm interesse em conhecer mais sobre o trabalho que eles realizam e a convivência em um ambiente acadêmico pode incentivá-los a continuar estudando e se profissionalizando. (Gabriela Fofonka)

25/10/2010 18:46:00

25/10/2010 18:57:00

O contador e o localizador revelam que as postagens em blog são acessadas. Esses fatos entusiasmam bastante os adolescentes autores, visto que percebem que seu trabalho é assistido, que seus textos são lidos. Lembramos aqui que os textos publicados até o momento se referem ao depoimento de alunos sobre sua participação no projeto. Com conteúdo revelador de construção de autoestima, exercício de cidadania e desenvolvimento de expressão.

Por outro lado, em algumas escolas vários professores solicitam ao coordenador da oficina de rádio que seja reproduzido e projetado em tela grande para o grupo de professores o trabalho publicado na web dos alunos de sua escola, ação já considerada costumeira. Orgulham-se os professores dos alunos da escola que possui rádio e produção divulgada. Vemos nesse caso a inclusão de produção escolar na Internet no formato de blog. Conferimos 
realização de expectativas, vemos alunos e pais assistindo em conjunto à projeção das produções através da rádio. Percebemos que famílias sem acesso à Internet em suas casas e sem manuseio de microcomputares estão conhecendo a comunicação em rede através da produção de seus filhos. Não a tínhamos desenhado uma expectativa dessas ações inicialmente, o processo nos premiou. Embora não tenhamos obtido a inserção em redes sociais, como comunidades específicas dos alunos das escolas, temos recebido seguidores no twitter a partir das publicações das peças produzidas pelos alunos. Portanto estamos presentes nas redes sociais e vamos ampliando nossa participação e reconhecimento pela perseverança revelada por esses meios digitais tão interessantes que localizam e quantificam nossos leitores.

Iniciamos um processo de construção de rede a partir da produção de programas para rodar no recreio das escolas. Falamos aqui da realização do Programa a Hora do Recreio (http:// alemrede.blogspot.com.br/p/ouca-as-radios.html). Operacionalmente consta da montagem de programas com entrevistas protagonizadas pelos alunos das escolas com objetivo de rodar em diferentes escolas. Neste caso uma escola pode ouvir os programas realizados pelos alunos de outra escola. Aqui propomos a interatividade resultado da fala de alunos aos seus pares.

Com a publicação dos alunos de várias escolas, reunidos num blog, damos os primeiros passos de realização de expectativas de interação da produção da rede municipal de forma mais abrangente nas várias escolas. Também consideramos esta uma rede social.

A rede social que nos referimos aqui é originária da produção dos alunos de diversas regiōes da cidade, obtendo a um só tempo a realização de um processo de educação e expressão. 


\section{Conclusões}

No campo que nos cabe, fazer acontecer o processo pedagógico na Rede Municipal de Educação, encargo de produzir a simbiose teoria/prática encontramos terreno para aplicação da Teoria da Educomunicação. Narramos a execução da proposta que envolve construção de veículos midiáticos nas escolas com intenção de propor ao aluno interação com colegas e publicação de sua produção em suportes veiculados pela Internet.

Neste propósito podemos conferir a realização, pelo menos em parte de nossas expectativas, e que é possível ao construir conhecimento associando educação e comunicação. Também percebemos que nossa expectativa esteve além do viável, entretanto, registramos e aprendemos que muito foi construído e pode vir a ser construído ainda mais na medida em que nos deparamos com diversos suportes de forte atração por parte de crianças e adolescentes.

Quanto à construção do Ecossistema Comunicativo estamos vivendo esta trajetória. Dela fazem parte conceitos que levam a perceber a realidade em que se vive e para construir soluçóes, num contexto de construção de melhor qualidade de relaçôes interpessoais e melhor convívio com o meio ambiente para a construção permanente de uma melhor qualidade de vida, construindo um ecossistema social com tendência de ser tão harmônico nos campos do social e a da natureza como a orientar uma ação de sustentabilidade inerente à qualidade de vida. Aspiraçóes como estas precisam materializar-se em processos educacionais.

Evidente que construções desse porte não se concluem de imediato, contudo revelam seu potencial de crescimento e confirmam a importância da perseverança como grau de conquista. 


\section{Referências}

AMARO, Lucia. Entrevista com estudante de jornalismo. Rádio DJTALD/ EMEF Chico Mendes. Porto Alegre: Secretaria Municipal de Educação de Porto Alegre, 2010. Disponível em: <http://djtaldemaiscm.blogspot.com. $\mathrm{br} / 2010 / 07 /$ entrevista-com-estudante-de-jornalismo.html>. Acesso em: 23 mar. 2012.

FREITAS, Jesualdo Freitas de. Educomunicação: possibilidades na escola através do Projeto Alunos em rede - mídias escolares. ÁGORA: revista virtual. Porto Alegre: Secretaria Municipal de Educação de Porto Alegre. Disponível em: <http://websmed.portoalegre.rs.gov.br/escolas/revistavirtualagora/educomunicacao.pdf $>$. Acesso em: 23 mar. 2012.

MORAES, André. Vídeo. Pré-conferência dos Direitos da Criança e do Adolescente da Região Partenon. Amigos do som: a rádio web do Marcírio. Porto Alegre: SMED/EMEF Dep. Marcírio Goulart Loureiro. Disponível em: <http://radioamigosdosom.blogspot.com.br/2011/08/preconferencia-dos-direitos-da-crianca.html>. Acesso em: 23 mar. 2012.

PEREIRA, Diego. Minhas impressões sobre o FLL BRASILEIRO 2010. Roboviagem: robótica educacional (inclusão digital). Porto Alegre: Secretaria Municipal de Educação de Porto Alegre. Disponível em: <http:// roboviagem2010.blogspot.com.br/>. Acesso em: 23 mar. 2012.

PREFEITURA MUNICIPAL DE PORTO ALEGRE. Secretaria Municipal de Educação de Porto Alegre. Projeto Alunos em rede: mídias escolares (inclusão digital). Disponível em: <http://alemrede.blogspot.com/>. Acesso em: 23 mar. 2012.

Secretaria Municipal de Educação de Porto Alegre. Projeto Alunos em rede: mídias escolares (inclusão digital). Escolas municipais no Laboratório de Áudio do IPA e também falando aos acadêmicos de Pedagogia e Jornalismo. Disponível em: <http://alemrede.blogspot.com. $\mathrm{br} / 2010 / 06 /$ escolas-municipais-nos-estudios-de.html $>$. Acesso em: 23 mar. 2012.

Secretaria Municipal de Educação de Porto Alegre. Projeto Alunos em rede: mídias escolares (inclusão digital). Ouça as rádios. Disponível em: <http://alemrede.blogspot.com.br/p/ouca-as-radios.html>. Acesso em: 23 mar. 2012. 
ROCHA, Bruna. Minhas impressões sobre o FLL BRASILEIRO 2010. Roboviagem: robótica educacional (inclusão digital). Porto Alegre: Secretaria Municipal de Educação de Porto Alegre. Disponível em: <http:// roboviagem 2010.blogspot.com.br/2010/12/minhas-impressoes-sobre-ofll.html>. Acesso em: 23 mar. 2012.

SANTOS, Ednara. Vacinação da Tríplice Viral no Marcírio. Amigos do som: a rádio web do Marcírio. Porto Alegre: SMED/EMEF Dep. Marcírio Goulart Loureiro. Disponível em: <http://radioamigosdosom.blogspot.com.br/search?updated-max=2011-08-20T12:20:00-03:00\&maxresults $=10 \&$ start $=10 \&$ by-date $=$ false $)>$. Acesso em: 23 mar. 2012.

VELASQUE, Ingrid. Pré-conferência dos Direitos da Criança e do Adolescente da Região Partenon. Amigos do som: a rádio web do Marcírio. Porto Alegre: SMED/EMEF Dep. Marcírio Goulart Loureiro. Disponível em: <http://radioamigosdosom.blogspot.com.br/2011/08/pre-conferenciados-direitos-da-crianca.html>. Acesso em: 23 mar. 2012. 